4961850

PREPARED FOR THE U.S. DEPARTMENT OF ENERGY,

PPPL-2774

UC-420 UNDER CONTRACT DE-AC02-76-CHO-3073

$(c, p \cdot),-s / s$

PPPL-2774

THE EFFECT OF LIMITER CONDITIONING ON THE TOKAMAK FUSION TEST REACTOR EDGE PLASMA

BY

S.J. KILPATRICK, ET AL.

July 1991
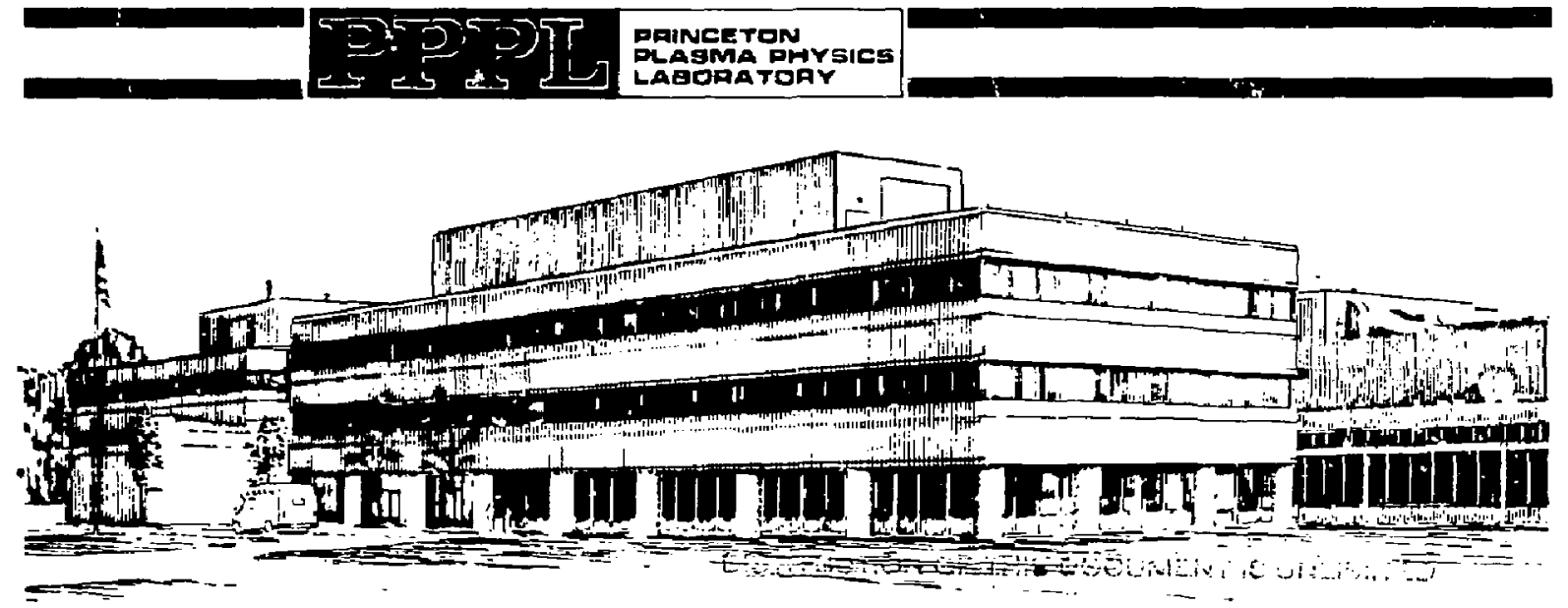

PRINCETON UNIVERSITY, PRINCETON, NÉW JERSEY Ĺ, 


\section{NOTICE}

This report was prepared as an account of work sponsored by an agency of the United States Government. Neither the United States Government nor any agency thereof, nor any of their employees, makes any warranty, express or implied, or assumes any legal liability or responsibility for the accuracy, completeness, or usefulness of any information, apparatus, product, or process disclosed, or represents that its use would not infringe privately owned rights. Reference herein to any specific commercial produce, process, or service by trade name, trademark, manufasturer, or otherwise, does not necessarily constitute or imply its endorsement, recommendation, or favoring by the United States Government or any agency thereof. The views and opinions of zuthors expressed herein do not necessarily state or reflect those of the United States Government or any agency thereof.

\section{NOTICE}

This report has been reproduced directly from the best available copy.

Available to DOE and DOE contractors from the:

Office of Scientific and Technical Information

P.O. Box 62

Oak Ridge, TN 37831;

Prices available from (615) 576-8401.

Available to the public from the:

National Technical Information Service

U.S. Department of Commerce

5285 Port Royal Road

Springfield, Virginia 22161

$703-487-4650$ 


\title{
THE EFFECT OF LIMITER CONDITIONING ON THE TOKAMAK FUSION TEST REACTOR EDGE PLASMA
}

\author{
S. J. Kilpatrick, C. S. Pitchera), H. F. Dyilab), D. M. Manos, 1. Nyberg, A. T. Ramsey, B. C. \\ Stratton, J. Timberlake, and M. J. Ulrickson \\ Princeton Plasma Physics Laboratory, Princeton, NJ 08543
}

\begin{abstract}
Measurements by moveable Langmuir probes and edge spectroscopy diagnostics have documen,ed the conditioning effect of low density helium-initiated discharge sequences on the Tokamak Fusion Test Reactor (TFTR) edge plasma. Langmuir probe measurements show in general that the edge electron density $n_{\theta}$ decreases by less than a factor of 2 white the edge electron temperature $T_{\theta}$ doubles. Radial profiles to the plasma boundary show that the density scrape-off length increases somewhat while the temperature scrape-off length decreases substantially. The particle flux density is unaffected. The spectral emission of $C$ II decreases by a factor of 2, a much smaller change than that exhibited by the $D_{\alpha}$ signal. These results complement previous accounts of the conditioning technique. Comparisons of these He conditioning measurements are made to edge measurements during a deuterium density scan experiment. showing many similarities, and to an existing edige model of the conditioning process, showing qualitative agreement.
\end{abstract}

(Presented at the 37th National Symposium of the American Vacuum Society, B-12 October 1990, Toronto, Canada, and accepted for publication in the Journal of Vacuum Science and Technology A.) 


\section{INTRQDUCTION}

Interactions between the plasma and the axisymmetric graphite bumper limiter on the inner wall of the Tokamak Fusion Test Reactor (TFTR), referred to as the inner limiter, have a strong effect on machine performance, particularly in the areas of impurily and particle recycling and control [ $t$ ]. With regard to the latter, Iypical plasma operation with deuterium fueling causes the near-surface region of the limiter to become saturated with hydrogenic species, which results in particle recycling coefficients near unity and limits the range of plasma density control. In 1986, a conditioning technique was found [2] which could remove a large fraction of the trapped gas. It consists of a series (20 - 30) of minimum density helium- (or deuterium-) initiated discharges (each discharge lasting generally 6 - 8 s) which, most likely, removes the hydrogenic species by an ion-induced desorption process [3,4]. By this process the line-average plasma density can be reduced to the recycling limit, $0.9 \times 10^{13} \mathrm{~cm}^{-3}$ for a plasma current. $I_{p}$ of $1.4 \mathrm{MA}$, and the recycling coefficient is reduced to values as low as 0.5 . This conditioning process was instrumental in discovering an enhanced confinement mode $[5,6]$ during high power neutral beam injection in which the density profile is highly peaked. He conditioning using 1.4 MA discharges has become a routine procedure for continuing these and other low-recycling experiments on TFTR.

Previous descriptions of limiter conditioning [1-2,7] have reported measurements of the plasma density, edge neutral pressure, $D_{\beta}$ emission, and integrated gas output (derived from pressure versus time data after each discharge). This paper focuses on Langmuir prove measurements of ion saturation current density, electron density, and electron temperature up to the plasma boundary and C II emission measurements at the inner watl. Section II gives experimental details, Section III summarizes the results, and Section IV compares these He conditioning measurements to earlier measurements on the scaling of edge quantities with central deuterium density and to an existing edge model.

\section{EXPERIMENTAL}

The data in this paper come from He conditioning discharges with $I_{p}=1.4 \mathrm{MA}, R=2.4 \mathrm{~s}$, and $a=0.80 \mathrm{~m}$, which contact the inner limiter. Only a small quantity of $\mathrm{He}$ is actually introduced for each discharge, enough for plasma breakdown; this plays no role in the characteristics of the discharge [2]. The discharge is sustained by deuterium and other species 
(e.g. carbon) which are removed from the limiter. In between discharges there is a significant amount of gas pumped out of the machine, as has been documented by Ulrickson et al. [7]. A conditioning sequence consists of several consecutive discharges (generally 20 - 30 , but depending on the starting condition of the inner limiter and the desired endpoint of the process). Measurements of the plasma loop voltage indicate that the Ohmic power input stays roughly constant during a conditioning sequence.

The Langmuir probe measurements were made with a fast moving probe mechanism [8] $(13 \mathrm{~cm} / \mathrm{s}$ ) mounted above the outer midplane, which acquired radial profiles to the plasma boundary in each discharge, and the CESEP (Combined Electrical and Sample Exposure Probe) diagnostic [9], which made stationary Langmuir probe measurements from a location below the plasma column and toroidally displaced by $-50^{\circ}$ from the fast probe. The Langmuir elements on the fast probe and the CESEP probe were graphite rods $6.4 \mathrm{~mm}$ and $2.8 \mathrm{~mm}$ in diameter, respectively, and were biased as double probes with a sinusoidal voltage at $60 \mathrm{~Hz}$. In the data analysis $[10]$ it was assumed that the electron and ion temperatures were equial $\left(T_{i}=T_{\theta}\right)$ and the ion mass was that for deuterium. The latter is generally a good assumption in the confined plasma in the early stages of a conditioning sequence, when the plasma density is high. However, near the end of conditioning. the plasma $Z_{\varepsilon f f}$ is nearly $6[11,12]$, being dominated by carbon sputtered from the timiter. We have no measurements of ion temperature, although it has been observed in the range of 2 - 3 times $T_{\theta}$ on other tokamaks [13] at low densities. If an average ion mass greater than mass 2 and $T_{i}>T_{\theta}$ were actually encountered during these measurements, then they would lead to errors in the calculations of $n_{\theta}$ as presented, but with opposing effects.

Measurements of $C$ II emission, as well as $D_{\alpha}$ emission, were made with an interference fijter array [11] and a visible spectrometer, both mounted radially at the outer midplane. The interterence filter array has a poloidal set of views toward the inner limiter, and data from this diagnostic are reported as a sum over the poloidal channels.

\section{EDGE MEASUREMENTS}

The effect of a typical 1.4 MA He conditioning sequence is illustrated by the decrease in the line-average plasma density $\bar{\pi}_{\mathbf{e}}$, the $D_{\alpha}$ emission, the $C$ II emission, and the edge electron density $n_{e}$, and the increase in the edge electron temperature $T_{\theta}$ as shown in Figure 1. The Langmuir data 
were taken with the CESEP probe $2.9 \mathrm{~cm}$ away from the plasma boundary llast closed flux surface (LCFS)], and the spectroscopy data came from the visible spectrometer system. The plasma density (a) at the starting point of this sequence, $\overline{n_{\theta}}=1.95 \times 10^{13} \mathrm{~cm}^{-3}$, was $\sim 50 \%$ lower than is sometimes observed in a $1.4 \mathrm{MA}$ conditioning discharge, which indicates that the limiter was not fully saturated with hydrogenic species. This is substantiated by a measurement of the electron density decay constant, $\tau_{p}$; before this sequence. It had a value of $200 \mathrm{~ms}$, short compared to typical values of several seconds for a saturated limiter [2]. $\tau_{p}^{*}$ decreased to 120 $\mathrm{ms}$ after the conditioning. There was only a small decrease in the C II emission (c) during the conditioning. We have observed that in a full condirioning sequence as shown in Figure 2, the $\mathrm{C} \|$ emission decreases by about a factor of 2 and the $D_{\alpha}$ emission drops by an order of magnitude. We surmise that the small change in $\mathrm{CII}$ in Fig. $1(\mathrm{C})$ is due to the lower starting point for the plasma density in that run. The Langmuir probe data in Fig. $1(d)$ and $I(e)$ show that $T_{\theta}$ increases by $-50 \%$ while $n_{e}$ decreases at a slightly slower rate than $\overline{n_{\theta}}$.

Figure 3 contains radial profiles from the fast probe of ion saturation current density for equivalently particle flux densityi. $I_{s}$, and electron density to the plasma boundary during selected discharges in a more recent 1.4MA He conditioning sequence. The highest and lowest values of $\overline{n_{\theta}}$ shown represent the start and termination of the sequence, respectively, which encompassed a total of only 13 discharges. The distance scale is assigned on the basis of nomirial magnetics measurements, where the zero position corresponds to the LCFS. The true plasma boundary is best ascertained by probe measurements of the floating potential across the boundary, as described in Ref. 14. Lacking such measurements for this case, the uncertainty in the location of the LCFS is at least $\pm 1 \mathrm{~cm}$. Extrapolating the data to this nominal LCFS yields $n_{\theta}(a)=2.0 \times$ $10^{12}$ and $1.2 \times 10^{12} \mathrm{~cm}^{-3}$ at the start and end of conditioning, respectively. The corresponding values for electron temperature are $T_{\theta}(a)=28$ and $60 \mathrm{eV}$, respectively (not shown). The ion saturation current density profile remained unchanged during this sequence, in agreement with measurements by Erents et al. [15] on the Joint European Torus (JET). The $n_{E}$ profile, meanwhile, showed considerable change, becoming flatter as the conditioning progressed, with a more pronounced effect closer to the plasma boundary. The plateau in the profiles at $-4 \mathrm{~cm}$ is thought to be due to some vacuum vessel component.

Scrape-off lengths were extracted from these Langmuir probe data assuming exponential 
behavior, and are plotted as a function of $\bar{\pi}_{\theta}$ in Figure 4 . The change in the density scrape-oft length. $\lambda_{n}$, from $-510 \geq 7 \mathrm{~cm}$ is modest compared to the large and opposite swing in the temperature scrape-off length, $\lambda_{T}$. Irom $\sim 21$ down to $7.8 \mathrm{~cm}$. As noted in Fig. 3. the particle scrape-off length, $\lambda_{p}$, did not change.

The scaling of $I_{S}, n_{\theta}$, and $T_{\theta}$ with $\overline{n_{e}}$ at the closest probe position for the discharges described in Figs. 3 and 4 is shown in Figure 5. Note that $\pi_{\theta}$ and $\tau_{\theta}$ are substantially lower than in Fig. 1, especially considering that those measurements were made $2.9 \mathrm{~cm}$ outside the LCFS. A number of factors may have contributed to this, including (1) poloidal asymmetries between the outer midplane and the bottom of the torus, including, magnetic surface compression, (2) uncertainties in the distance 10 the LCFS, and (3) differing machine conditions, especially those caused by slight changes in the inner limiter configuration [16] between the two conditioning runs. The $D_{\alpha}$ and $C \|$ signals acquired by the interference filter array looked similar to those in Fig. 2, although the $D_{\alpha}$ intensity fell more rapidly in this case.

\section{DISCUSSION}

The data presented in Fig. 5, plotted as a function of plasma density, are similar to data obtained during a deuterium density scan experiment [17]. The density scan began with low plasma densities, and gas was purposely added in successive discharges to raise the density from the recycling limit up to the density limit. At similar densities very similar values of $n_{\theta}(a)$ and $T_{0}$ (a) were obtained with the fast probe for both the He conditioning and the $D_{2}$ density scan discharges. In addition, the spectral emissions of $D_{\alpha}$ and $C$ II are similar for the He and $D_{2}$ discharges.

In such a density scan, starting with a depleted limiter and raising the density by gas injection, the limiter pumps deuterium and makes it necessary to maintain a gas feed to establish a constant plasma density. In contrast, for the data presented in this paper, no gas injection was used; the densiiy remained at a constant value through unity recycling of deuterium and carbon incident on the limiter. Despite this difference, the results are similar in the two scans. This is explained by the fact that although gas injection was used in the density scan, the magnitude of the gas puff was small compared to the amount of deuterium recycling at the limiter and thus had 
little effect on the power and particle balance, resulting in similar values of edge parameters.

The trends shown in Figs. 1 and 2 are qualitatively similar to those predicted by Pitcher with a simple model of power and particle balance [18]. The model takes into account (1) the balance between the devterium in the graphite limiter surface (based on a model by Möller and Scherzer [19]) with the deuterium in the plasma, (2) the erosion and redeposition of carbon impurities produced at the limiter by deuteron and carbon physical sputtering, and (3) the balance of input power with radiated power and power deposited on the limiter by the thermal boundary plasma. What is not included in the model is the process by which $D_{2}$ gas permanently leaves the limiter or becomes unavailable for further desorption. The physics behind this process are only poorly understood. However, if the gas leaving the system is taken as an input to the mode! then the observed trends can be understood and predicted using these simple power and pa:ticle balance considerations.

Al the highest density the limiter is fully saturated, with the ratio of hydrogenic species (mostly Jeuterium) to carbon atoms being approximately 0.4 [20]. As the surface is depleted of gas, the amount of deuterium available for desorption drops sharply, resulting in a decrease in the $D_{\alpha}$ signal as shown in Fig. 2 . As a result of the decreased fueling, both the edge density and the central density decrease through the conditioning sequence.

Since the power input is constant $(-t \mathrm{MW})$, the decrease in the particle flux requires, through the power balance, that the particle energies increase, which is observed in the edge eleurson temperature increase shown in Fig. 1. The increase in $T_{\theta}$ results in an increase in the effective sputtering yield at the limiter. Thus, although the $\mathrm{C} / 1$ signal (roughly interpreted as a measure of the carbon influx) decreases with the $D_{\alpha}$ signal, its decrease is more gradual due to the compensating effect of increased sputtering yield. At the end of the conditioning sequence, the amount of gas leaving the torus between discharges becomes very small, thus halting further evolution of the discharge parameters.

\section{CONCLUSIONS}

We have described the evolution of some edge parameters during helium conditioning on TFTR, focusing on Langmuir probe measurements up to the plasma boundary and spectroscopic measurements of $\mathrm{C} \|$ emission at the inner limiter. In general the edge electron density decreases 
by less than a factor of 2 while the edge electron temperature doubles. Measurements near the outer midplane showed $n_{\theta}(a)$ decreasing from $2.0 \times 10^{12}$ to $1.2 \times 10^{12} \mathrm{~cm}^{-3}$ and $T_{\theta}(a)$ increasing from 28 to $60 \mathrm{eV}$. The magnitude of these changes depe.as on the extent of the conditioning performed. The radial profiles of these quantities change also: the density profile broadens $\left(\lambda_{n}\right.$ increases from $\left.-510 \geq 7 \mathrm{~cm}\right)$, and the lemperature profile narrows ( $\lambda_{T}$ decreases from -21 to $7.8 \mathrm{~cm}$ ). The particle flux density near the boundary is unaffecled. The $C \|$ emission decreases by a factor of 2 , which is a smaller change than the decrease in the $D_{\alpha}$ emission due to the mitigating effect of the increasing carbon sputtering yield. These results were quite similar to those from a deuterium density scan experiment, and were in qualitative agreement with an existing model of power and particle balance.

\section{ACKNOWLEDGMENT}

This work was supported by the U. S. Department of Energy Contract No. DE.AC02-76-CHO-3073. 


\section{REFERENCES}

a) Permanent address: Canadian Fusion Fuels Technology Project, Toronto, Canada

b) Present address: CEBAF Center, Newport News, VA 23606

1. H. F. Dylla, M. Ulrickson, M. G. Bell, D. K. Owens, D. Buchenauer el al, J. Nucl. Mater, 162.164, 128 (1989).

2. H. F. Dylla, P. H. LaMarche, M. Ulrickson, R. J. Goldston, D. B. Heifetz el al. Nuct. Fusion 27. 1221 (1987).

3. R. A. Langley, J. Nucl. Mater. 162-164, 1030 (1989).

4. W. R. Wampler and S. M. Myers, J. Nucl. Mater. 111\& \&112, 616 (1982).

5. J. D. Strachan, M. Bitter, A. T. Ramsey, M. C. Zarnsiorf, V. Arunasalam el al. Phys. Rev. Lett. 58. 1004 (1987).

6. R. J. Goldston, V. Arunasalam, M. G. Bell, M. Bitter, W. R. Blanchard etal, in Proceedinos of the 11th international Conference on Plasma Physics and Controlled Nuclear Fusion Besearch, Kyoto, 1986 (IAEA, Vienna, 1987) Paper No. IAEA-CN-47/A-II-1.

7. M. Ulrickson, H. F. Dylla. P. H. LaMarche, and D. Buchenauer, J. Vac. Sci. Technol. A6, 2001 (1988).

8. O. M. Manos and S. J. Kilpatrick, in Process Diaonostics: Materials Combustion. Fusion [Materials Research Society Symposium Proceedings, vol. 117, Ed. A. K. Hays] (Materials Research Society, Pittsburg, 1988) p. 263.

9. R. Mastronardi, R. Cabral, and D. Manos, in Proceedings of the 10th Symposium on Fusion Engineering. Philadelphia, 1983 (IEEE, New York, 1983). p. 1507.

10. D. M. Manos and G. M. McCracken, in Plasma Wall Interactions in Controlled Fusion Devices, edited by R. Behrisch and D. Post (Plenum, New York, 1986).

11. A. T. Ramsey and S. L. Turner, Rev. Sci. Instrum. 5B, 1211 (1987).

12. K. W. Hill, V. Arunasalam, M. G. Bell, M. Bitter, W. R. Blanchard eltal., in Proceedinos of the 11 h International Coiference en Plasma Physics and Controlled Nuclear Fusion Research. Kyolo, 1986 (IAEA, Vienna, 1987) Paper No. IAEA-CN-47/A-IV-2.

13. R. A. Pitts. G. M. McCracken G. F. Matthews, and S. J. Fielding, in Proceedinos of the 161h European Conference on controlled Fusion and Plasma Physics, Venice, 1989 (European Physical Society, Geneva, 1989), Part III, p. 955.

14. S. J. Kilpatrick, G. S. Pitcher, M. G. Bell, D. M. Manos, D. K. Mansfield el al, J. Vac. Sci Technol.A8, 1767 (1990).

15. S. K. Erenis, J. A. Tagle, G. M. McCracken, P. C. Stangeby, and L. de Kock, Nucl. Fusion 28. 


$$
1209 \text { (1988). }
$$

16. G. Barnes, D. Loesser, D. K. Owens, and M. Ulrickson, in Proceedinas of the 13th Symposium on Fusion Enoineering Knoxville, 1989 (IEEE, New York, 1990), p. 937.

17. C. S. Pitcher, R. V. Budny, K. W. Hill, S. J. Kilpatrick, D. M. Manos et_al, Bull. Am. Phys. Soc 35, 2089 (1990).

18. C. S. Pitcher, unpublished.

19. W. Mölier and B. M. U. Scherzer, J. Appl. Phys. 64, 4860 (1988).

20. W. R. Wampler, D. K. Brice, and C. W. Magee, J. Nucl. Mater. 102, 304 (1981). 


\section{FIGURE CAPTIONS}

Fig. 1 Measurements of (a) plasma density, (b) $D_{c}$ emission, (c) $C$ II amission, (d) edge electron density, and $(\theta)$ edge electron temperalure during a $1.4 \mathrm{Mr}$ He conditioning sequence. The error bars for: $r_{\theta}$ and $T_{\theta}$ represent the $95 \%$ con:idience intervals for the fitted data.

Fig. 2 The change in the $C$ if and $D_{\alpha}$ intensities duriry a full conditioning sequence as measured by the interference filter array.

Fig. 3 Fadial profiles of ion saturation curyent density and edge electron densify for selected discharges during a conditioning : ^ann.

Fig. 4 Plasma density varianon $o_{1}$ the scrape-off lengths tor $I_{s}, n_{\theta}$, and $T_{\theta}$ during the conditioning scan tof Fig. 3.

Fig. 5 Plasma densı!y variation of (a) the ion saturation current density, (b) the edge electron density, and (c) ins edge electron lemperature during the cunditioning scan of Fig. 3. 
PPPL $90 \times 0502$
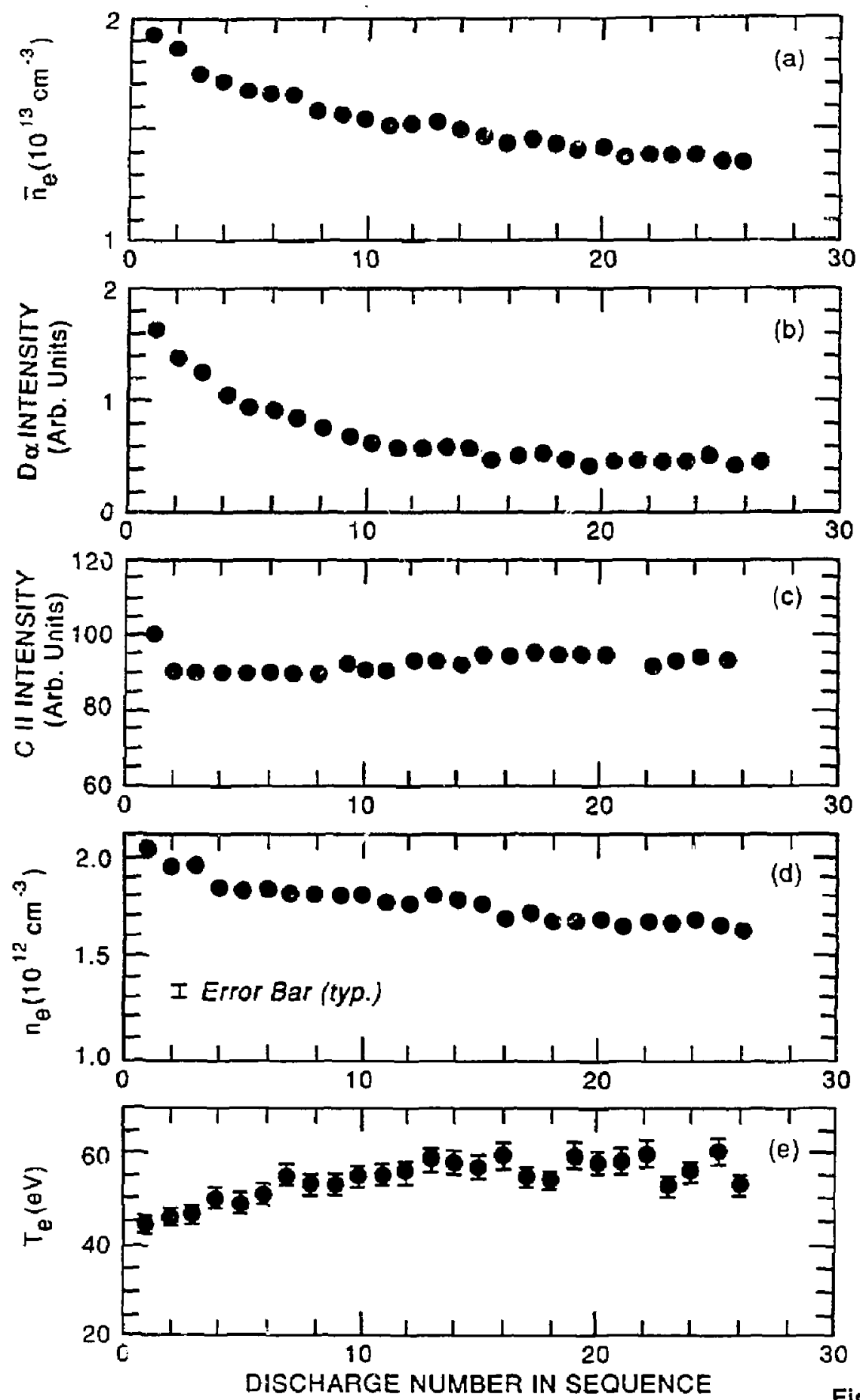

Figure 1 
PPPL\#90X0503

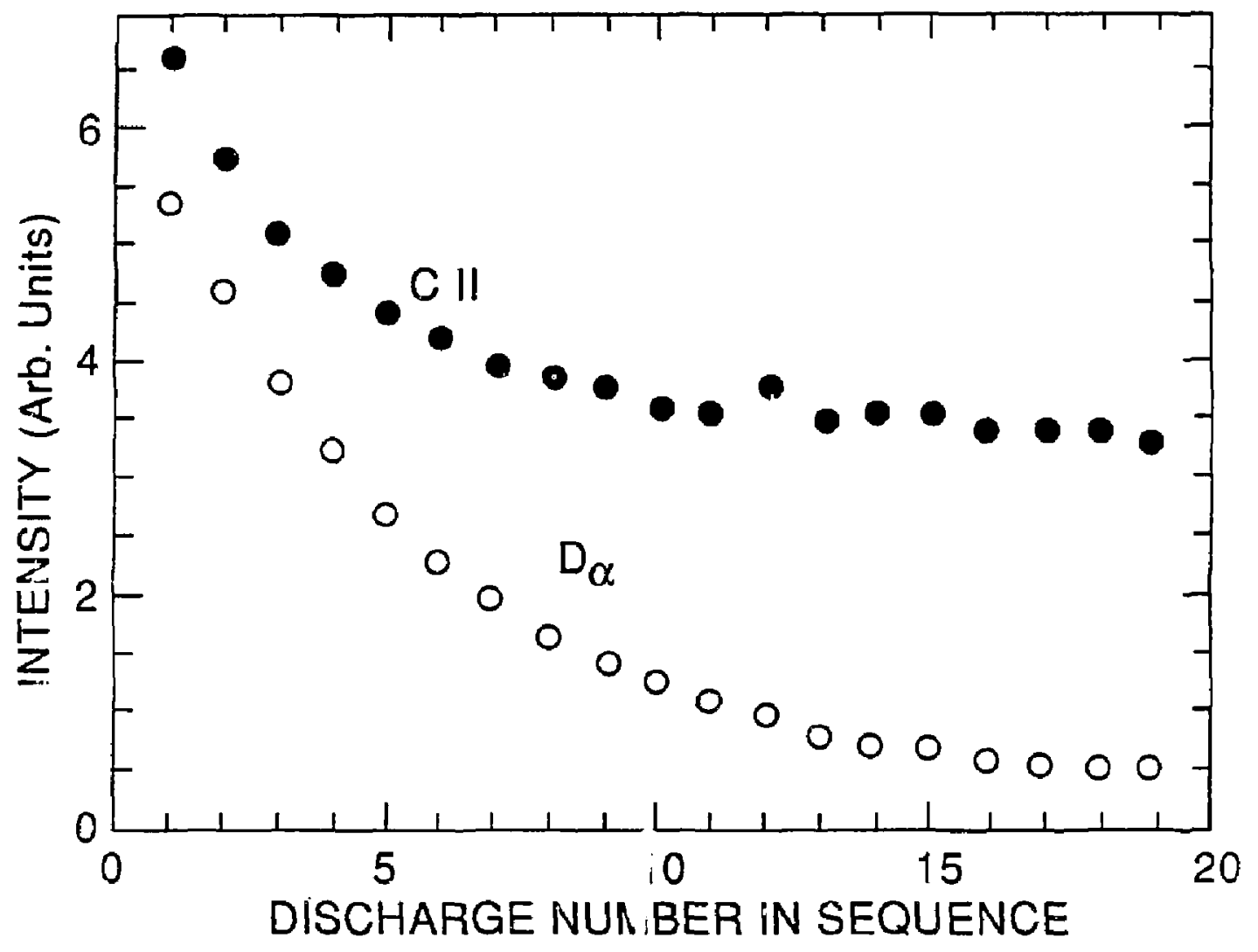

Figure 2 

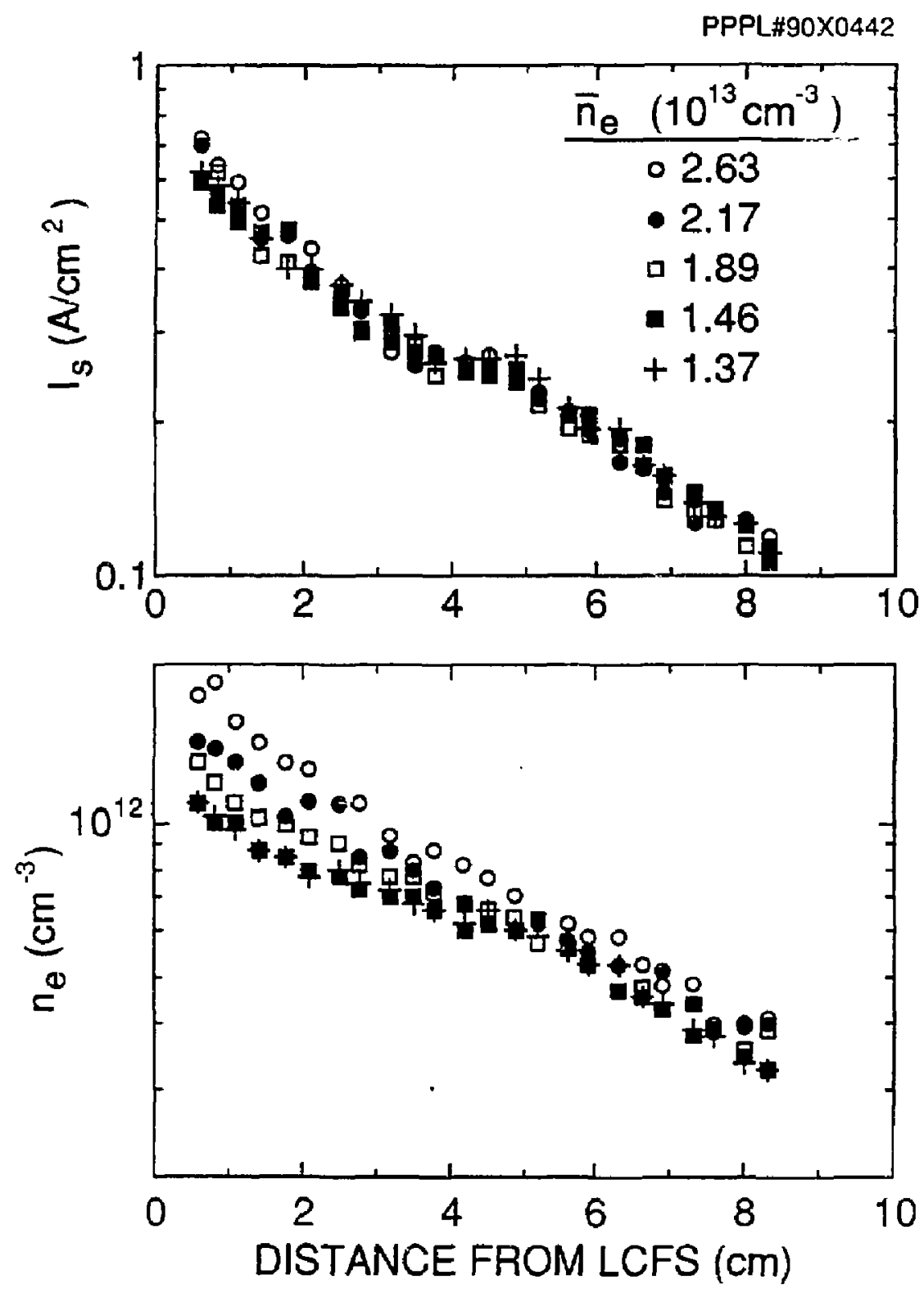

Figure 3 


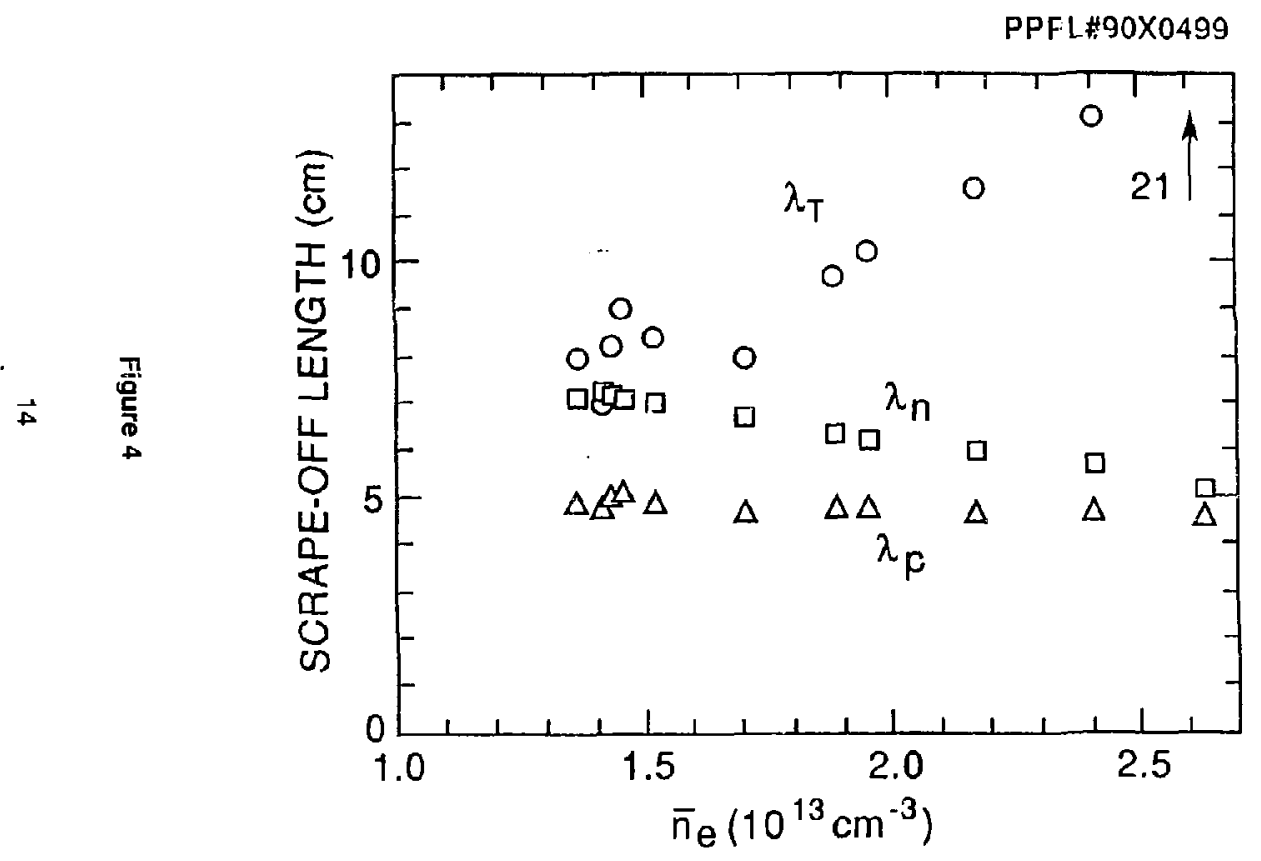



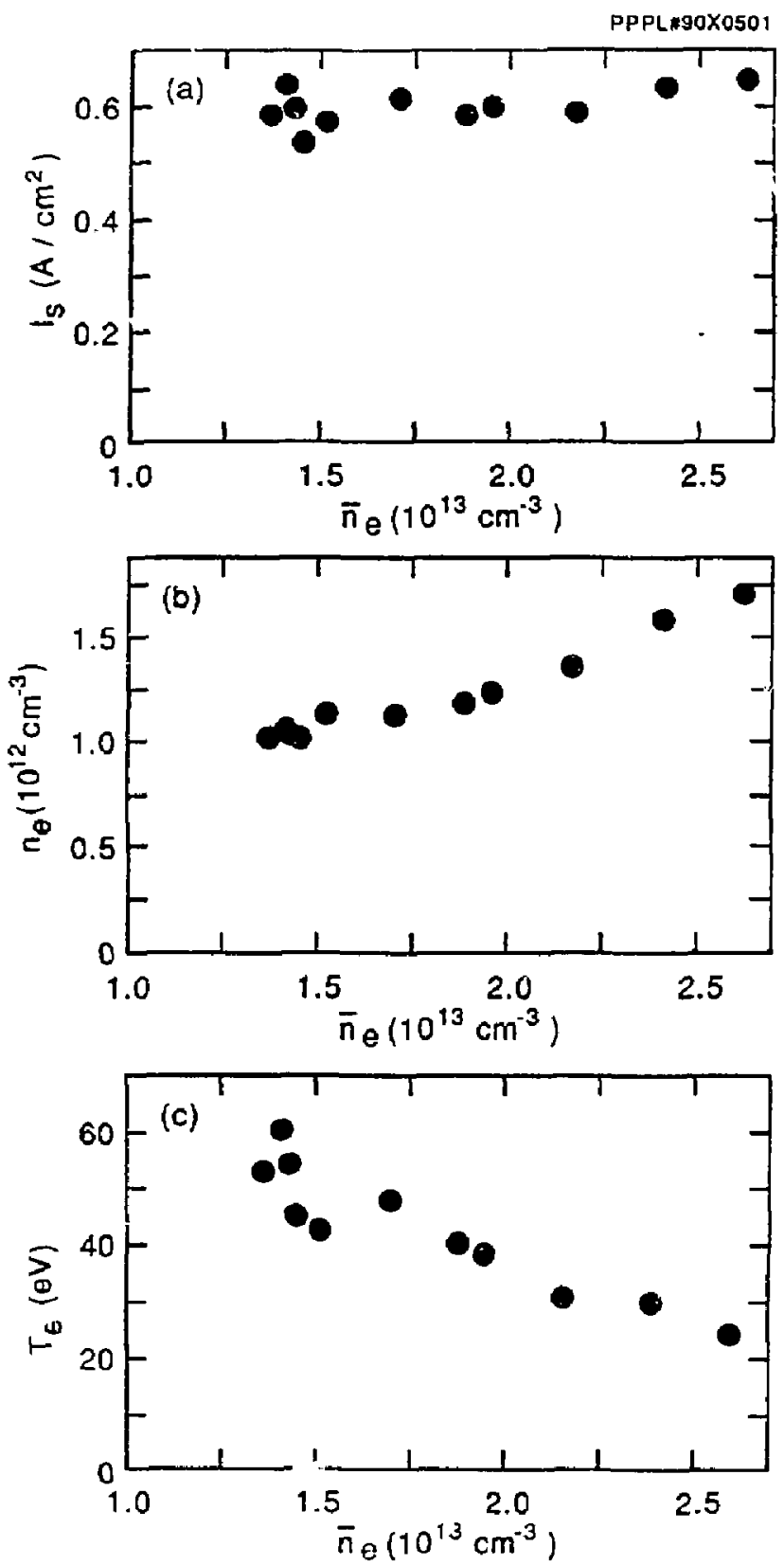

Figure 5 
Dr. F. Paoloni, Uniry of Wollongong. AUSTRALIA

Prol. M.H. Brennen. Univ. of Sydney. AUSTRALIA Plasma Feseareh Lab., Australian Nar. Univ.. AUSTRALIA

Prot 1.A. Jores. Flinders Univ. AUSTRALA

Prof. F Cap. Inst. tor Theoretical Physics, AUSTRIA

Prot. M. Heindler. Institut für Theoretische Physik, AUSTRIA

Prof. M. Goossens, Astronomisch Instituut, gELGIUM

Ecole Aoyale Militare, Lab. de Phy. Plasmas. BELGILM

Commission-Europoan, OG. XI1-Fusiun Prog., BELGIUM

Prot. R. Bouciaje. Rijksuniversiteit Gent. BELGIUM

Dr. P.H. Sakanaka, Instituto Fisica, BFAZIL

instinuto do Pesquisas Espaciais-INPE, BRAZIL

Documents Otfice, Atomic Energy of Canada LId., CANADA

Dr. M.P. Bachynski, MPg Techrologies, Inc, GANADA

Or. H.M. Skarsgard. Uny. of Saskatchowan, CANADA

Prof. J. Teichmann, Univ. of Montroal, GANADA

Prot. S.R. Sreenivasan. Univ. of Calgay. CANADA

Prof. T.W. Johnston, INAS-Energie, CANADA

Dr. A. Bolton, Centre canadien de husion magnéique, CANADA

Dr. C.R. James,., Uny. ol Alborta, CANAOA

Or. P Lukac, Komenskeho Universzita, CZECHOSLOVAKIA

The Librarian, Culinam Laboratory. ENGLAND

Library. R61, Ruthertord Appleton Laboratory. ENGLAND

Mrs. S.A. Hutehinson, JET Library. ENGLAND

P. Makdonen. Univ. of Helsink, FINLAND

C Moutrot, Lab de Physique dos Milieux lonises, FAANCE

$\checkmark$ Radet, CEN/CADAFACHE - Bat 506, FRANCE

Ms. C. Pinni, Univ. of raannina GREECE

Dr. T. Mual, Acadomy Bibliographic Ser., HONG KONG

Preprint Library, Hungarian Academy of Sci., HUNGARY

Dr. B. Das Gupta, Sana Inst. of Nucdear Physies, INDIA

Dr P. Kaw, Inst. tor Plasma Research, INDIA

Or. P. Rosenau. Israsi Inst. of Technology. ISRAEL

Libranan. Intemational Center for Theo Physios, ITALY

Miss C. De Palo, Associazione EURATOM-ENEA, ITALY

Dr. G. Grosso, Istituto di Fisica dol Plasma, ITALY

Dr. H. Yamato. Toshiba Res \& Devel Contor. JAPAN

Prot. I. Kawakami, Awomic Energy Fes.Inst. JaPAN

Prof. K. Nishikawa, Hiroshima Univ.. JAPAN
Directer, Japan Alome Energy Research Inst., JAPAN

Prat. 5. Itoh. Kyushu Univ., JAPAN

Data and Planning Conter. Nagoya UnIv. JAPAN

Prot. S. Tanaka, Kyoto Univ.. JAPAN

Library, Kyoto Univ., JAPAN

Prof. N. Inoue. Univ. of Tokyo. JAPAN

S. Mori, Technical Advisor, JAERI, JAPAN

O. Mitara, Kumamolo inst. of Technology. JAPAN

H. Jeong. Korea Advanced Energy Research Inst., KOREA

Prof. D.I. Choi. The Korea Adv. Inst. of Sc. \& Tech. KOREA

Prol. B.S. Lilay, Univ. of Waikato. NEW ZEALAND

inst. of Plasma Physics, PEOPLE'S REPUELIC OF CHINA Libratan. Inst of Physics, PEOPLE'S REPUBLJC OF CHINA Library. Tsinghu Univ., PEOPLESS REPUBLIC OF CHINA Z. L. S.W. Inst Pnysics. PEOPLE'S REPUBLIC OF CHINA Prot. J.A.C. Cabra, Inssuto Superice Tecrico. POATUGAL Dr. O. Petrus. Al I CUZA Univ. ROMANIA Dr. J. do Villiers, Fusion Studies. AEC. S. AFRICA

Prof. M.A. Heliberg, Univ, of Natal, S AfRICA

C.I.E.M.A.T, Fusion Division Library, SPAIN

Dr. L Stenflo, Uni.t. of UMEA, SWEDEN

Library, Royal Inst. of Technology, SWEDEN

Prof. H. Wilhaimsen, Chalmers Univ. at Tech. SWEDEN Centre Phys. Des Plasmas, Ecole Polytech. SWITZEriLAND Bibliotheok, Inst. Voor Plasma-Fysica. THE NETHERLANDS M. Durguz, Vioa Chairman. Middle East Tech Univ. TURKEY Dr. D.D. Ryutov, Siberian Branch ol Academy of Sci., USSR Or. G.A. Eliseev. Kurchatov inst, USSA Libranan, The Uks.SSR Academy ot Sciences. USSR Or. LM Kovrizhnykh, Inst of Genaral Physies, USSR Kemtorschungsanlage GmbH. Zentralbibliothek. W. GERMANY Giblicihek, Inst. Für Plasmatorschung. W. GERMANY Prol. K. Schindter, Ruhr-Universitat Bochum. W. GEAMANY Dr. F. Wagner. (ASDEX), Max-Pianck-Instut. W. GERMANY Librarian, Max-Planck-Institut, W. GERMANY Prot. R.K. Janev, inst. of Physies, YUgoslavia 